\title{
ONCOPLASTIC TECHNIQUES FOR EARLY UPPER INNER QUADRANT BREAST CANCER; A COMPARATIVE STUDY BETWEEN INFERIOR PEDICLE MAMMAPLASTY AND DOUGHNUT MASTOPEXY
}

\author{
Osama Ali El Atrash, Ahmad Gamal El Din Osman, Sherif Mohammed Mohsen \\ Ismail, and Bishoy Refaat Ragheb Ayoub
}

\begin{abstract}
Department of General Surgery, Faculty of Medicine -Ain Shams, Cairo - Egypt

\section{Corresponds:}

Bishoy Refaat Ragheb Ayoub

E.male:

drbishyrr@gmail.com

Tel.: 01018054123;
\end{abstract}

Received: 5/3/2019

Accepted: 1/4/2019

\begin{abstract}
Background: Breast conserving treatment (BCT) has become the standard treatment in early breast cancer; its goal is to provide a treatment as effective as mastectomy with the added benefit of a preserved breast. However, it is sometimes difficult to achieve good cosmetic results, particularly in patients with breast cancer located in the upper inner quadrant, for which the traditional conservative surgery results in a deformed breast.
\end{abstract}

Aim of the work: To compare prospectively the oncoplastic results of inferior pedicle mammaplasty and doughnut mastopexy as techniques for early breast cancers located at the upper inner quadrant.

Patients and Methods: This is a prospective randomized study on twenty female patients who were diagnosed to have early breast cancer located in the upper inner quadrant and are candidates for oncoplastic breast surgery. The study was conducted at Ain Shams University Hospitals. Approval of the Ethical Committee and written informed consent from all participants were obtained. Patient selection was achieved through a number of inclusion and exclusion criteria.

Results: There is significant difference between the two groups as regards the operative time, intraoperative blood loss, hospital stay, total drainage volume, drainage days, postoperative complications, cosmetic outcome and the need for contralateral symmetrization. Inferior pedicle mammaplasty needs longer operative time and postoperative hospital stay and drainagy days with more intraoperative blood loss in comparison to Doughnut mastopexy. As regards the postoperative complications, we found that there are more complications in Inferior pedicle mammaplasty than Doughnut mastopexy as wound wound infection and dehiscence.

Conclusion: Patients with early breast cancer located in the upper inner quadrant are candidate for either Inferior pedicle mammaplasty or Doughnut mastopexy. Doughnut mastopexy is better for them as there is less morbidity, better cosmesis, no need for contralateral symmetrization and fewer complications, so no delay in radiotherapy and Inferior pedicle mammaplasty needs more surgeon experience.

Keywords: Oncoplastic breast surgery, upper inner quadrant breast cancer, inferior pedicle mammaplasty, doughnut mastopexy. 


\section{INTRODUCTION}

The breast is the true mirror of femininity, and it remains in the mind of every one of us as the heart of womanhood, with its role as nourisher, and comforter. These roles evoke the idea of the importance and the affection of this delicate organ has in the minds of women ${ }^{(1)}$.

Breast cancer is predicted to be the most common newly diagnosed cancer in women and accounts for $29 \%$ of all cancers in women $^{(2)}$.

In Egypt, the rate of breast cancer is higher than the worldwide records representing $32.04 \%$ of female diagnosed cancers. More importantly; it has been reported that $49.7 \%$ of the Egyptian patients have regional spread at the time of diagnosis and $11.9 \%$ of them have distant metastasis ${ }^{(3)}$.

When a woman is diagnosed with breast cancer many aspects of her physical, emotional and sexual wholeness are threatened and she experiences a lifethreatening issue by facing the mortality of the disease as well ${ }^{(4)}$.

Cases of breast cancer have been recorded in medical writings for more than 5000 years. In documents from the ancient word, they appear with perhaps greater frequency than any other form of cancer. This suggests that the frequency of breast cancer was significant. The first written evidence suggestive of breast cancer is from ancient Egypt and is found in the Edwin Smith and Ebers Papyrus, dating back from 3000 to $2500 \mathrm{BC}^{(5)}$.

Radical mastectomy, a procedure conceived and popularized by William S. Halsted as the surgical treatment for breast cancer. It removes the entire breast, the underlying pectoral muscles and the axillary lymph nodes, leaving behind a depression under the clavicle, prominent ribs and a markedly deformed patient and it was referred to as "The operation women fear most". Later, the modified radical mastectomy became popular; not because there was a prospective randomized trial proving its equality, but rather because the Women's Movement, frustrated with years of mutilation, had pressed for the change ${ }^{(6)}$.

The approval of breast conserving surgery by the World Health Organization Committee of Investigations for Evaluation of Methods of Diagnosis and Treatment of Breast Cancer since 1996 has offered an alternative treatment method for early breast cancer besides radical mastectomy ${ }^{(7)}$.

Breast conserving surgery, defined as "complete removal of the breast issue with a concentric margin of surrounding healthy issue performed in a cosmetically acceptable manner (lumpectomy) usually followed by radiation therapy", became the standard therapy for low grade breast cancer. It is safe and preferred in all early detected breast cancers as it provides the same level of overall survival as mastectomy. This is found by several prospective and randomized studies and number of clinical trials. Besides that, it offers higher quality of life by reducing the impact of psychosocial adjustment, body image and sexual function caused by mastectomy ${ }^{(8)}$.

It is expected that around $30 \%$ of all breast conserving surgeries bring late aesthetic results that are considered unsatisfactory. The choice for preventive measures that have integrated techniques of plastic surgery into breast cancer surgery is changing this reality. Therefore, oncoplastic surgery is considered as tumor specific immediate breast reconstruction in order to optimize surgical planning ${ }^{(9)}$.

Audretsch, by the early 90's, suggested the integration of plastic surgery techniques with breast-conserving treatment for breast cancer. Conceptually, this approach was referred as "oncoplastic surgery", which aims at providing safe oncologic treatment through careful pre-operative planning and the incorporation of plastic surgery 
techniques in order to obtain good oncologic control with favorable cosmetic results in cases of large breast volume ${ }^{(10)}$.

The term "oncoplastic" was first introduced in the literature by Gabka et al. in 1997 to expand the spectrum of the indication for BCS. Oncoplastic surgery involves more than just the combination of oncologic principles with plastic techniques, as surgeons can perform larger excisions with free margins using various mammoplastic methods of remodeling the remaining breast tissue ${ }^{(7)}$.

Oncoplastic surgery represents a major advance in breast cancer surgery and has been receiving a widespread acceptance in breast conserving surgery. It is based on three principles: ideal breast cancer surgery with wider excisions, immediate breast reconstruction and immediate symmetry of the other breast, whenever necessary ${ }^{(9)}$.

Therefore, oncoplastic surgery is considered as the "third pathway" between breast conserving surgery and mastectomy (11).

Among others, lesions located in the upper inner quadrant of the breast deserve the most attention; a wide excision in this location can have a significant impact on the overall quality of the breast shape by distorting the visible breast line ${ }^{(7)}$.

Large defects in the upper inner quadrant of the breast will shift the nipple in an unnatural upward or medial fashion. That's why oncoplastic surgery is of special immportance in managing breast bancer located at the upper inner quadrant, the area known as the no man's land ${ }^{(12)}$.

If the tumor is in the upper inner quadrant of the breast and there is concern about creating unfavorable results from a cosmetic standpoint with lumpectomy alone, then inferior pedicle mammoplasty is preferable. Inferior pedicle oncoplastic procedure for upper inner tumors allows the surgeon to obtain negative margins with a large resection and the breast is kept well from the aethetic point of view. The inferior pedicle can reliably keep the nipple-areolar complex well perfused in a breast of almost any size and shape ${ }^{(13)}$.

Doughnut mastopexy is a surgical method which begins with a periareolar incision, but then proceeds to deepithelialize the periareolar skin in a doughnut shape. It is considered a useful alternative to standard lumpectomy because the periareolar scar is more discreet than a scar resulting from direct incision over the affected area, and has an overall more pleasing aesthetic result. Also, the glandular volume is rearranged with doughnut mastopexy to create a pleasing breast contour, and breast skin is reshaped as well $^{(14)}$.

\section{AIM OF THE WORK}

The aim of this work is to compare prospectively the oncoplastic results of inferior pedicle mammaplasty and doughnut mastopexy as techniques for early breast cancers located at the upper inner quadrant.

\section{PATIENTS AND METHODS}

Type of the study: This is a prospective randomized study on twenty female patients who were diagnosed to have early breast cancer located in the upper inner quadrant and are candidates for oncoplastic breast surgery.

Study settings: The study was conducted at Ain Shams University Hospitals. Approval of the Ethical Committee and written informed consent from all participants were obtained. Patient selection was achieved through a number of inclusion and exclusion criteria.

Inclusion criteria: Female patients of age ranging from $18-70$ years old. Primary breast malignancy stage I and II (Manchester) or T2 N1 M0 or less (TNM classification). Upper inner quadrant lesions. 
Imaging studies confirming patho-anatomic features corresponding to clinical symptoms. Histopathological diagnosis confirming the clinical features and manifestations. Downgraded tumors by neoadjuvant therapy.

Exclusion criteria: Male patients and female patients below the age of 18 years and above 70 years. Advanced primary breast cancer stage III, IV (Manchester) or T2 N1 $\mathrm{M} 0$ or more (TNM classification) with nipple and areola involvement including Paget disease of the nipple. Multicenteric lesion. Recurrent malignancy following conservative breast surgery. Inflammatory breast cancer with extensive skin involvement. Previous breast irradiation. Patient refusing conservative breast surgery.

Patients were subdivided by sealed envelope method into: 2 groups: Group I: This group is composed of ten patients that underwent Doughnut Mastopexy with the removal of the mass with safety margin and followed up postoperatively to detect any complication, assess aesthetic outcome and to detect recurrence. Group II: This group is composed of ten patients that underwent Inferior Pedicle Mammaplasty for removal of the mass with safety margin and followed up postoperatively to detect any complication, assess aesthetic outcome and to detect recurrence. All patients in both groups included in our study were compared for:

Intra-Operatively: Operative time. Blood loss. Contralateral symmetrisation.

Post-Operatively: Drainage volume. Drainage days. Hospital stay. Development of seroma and estimating the total seroma volume. Development of wound hematoma. Wound infection. Development of NAC necrosis. Wound dehiscence. Cosmetic outcome. Local recurrence.

All patients included in the study were subjected to the following:

Clinical assessment: Detailed medical, surgical, menstrual and family history. History of intake of oral contraceptive pills or hormonal replacement therapy with estrogen and progesterone. General examination. Full breast and axillary examination.

Investigations: Routine laboratory investigations. Bilateral sonomammography. Abdominal and pelvic ultrasound. Chest x-ray. Histopathological examination for the suspicious breast mass. MRI Breast for patients with invasive lobular carcinoma.

Multi-disciplinary team: Multidisciplinary team at the breast unit at General Surgery Department of Ain Shams University reviewed every single case independently. The MDT Included: breast surgery consultant, pathology consultant and radiology consultant. Discussion was made up upon every case including her history, examination and investigations.

Patient counseling and consent: After admission and completion of history and examination, each patient received a detailed explanation of her condition regarding the disease itself, the type of surgery and expected postoperative adjuvant therapy. Operative details of both surgical techniques were explained for each patient using pictures of similar cases to help visualization of the outcome, risks and benefits of the procedures. Possible complications were also clearly stated and explained individually for each procedure. Also the need for post-operative radiation dose to the remaining tissue of the breast and the resultant effect of this dose on the skin and cosmetic outcome was explained. All patients were evaluated by our surgical team prior to surgery, full photography of the breast were taken from multiple views. A formal consent was written and explained to the patient. The consent was signed one day prior to surgery and any inquiries, concerns or doubts were discussed with the patient and a first degree relative (upon the patient's request).

Medical photography: The need for medical photography was also discussed and explained. How will the photography be taken, 
and who is going to photograph her. Also the reason of the photography was discussed, explained and consented. Medical photos were taken and kept in the patient's records as agreed upon. Pictures were taken to the patients along their follow-up visits to keep record and document progress.

Surgical Techniques: 1. Group I: Dougnut mastopexy with the removal of the mass with safety margin and axillary resection of level I \& II lymph nodes.

2. Group II: Reduction mammoplasty with the removal of the mass with safety margin and axillary resection of level I \& II lymph nodes.

\section{Operative technique:}

Doughnut mastopexy: The procedure starts by making two concentric periareolar incisions, followed by de-epithelialization of the intervening skin. The outer edge of deepithelialized skin is incised and the entire skin envelope can then be undermined to allow access to the tumour. The NAC remains vascularized through its posterior glandular base. Resection of the lesion from the subcutaneous tissue down to the pectoralis fascia is performed and this results in the formation of an external and internal glandular flap. The flaps are then mobilized off the pectoralis fascia and advanced towards each other to eliminate the excision defect, the two incisions are then approximated, resulting in a periareolar scar. Axillary dissection starts from a separate transverse incision along hair line is used, the incision is placed approximately 4-5 $\mathrm{cm}$ below the most superior aspect of the axilla. The incision is extended anteriorly to the lateral border of the pectoralis major muscle and posteriorly to the latissimus dorsi muscle. A plane of dissection was created along the inferior border of the axillary vein and all fat, lymphatics, blood vessels were dissected off the axillary vein sparing the thoracodorsal pedicle and long thoracic nerve. Closure with drain end fixed to the skin with non-absorbable sutures.
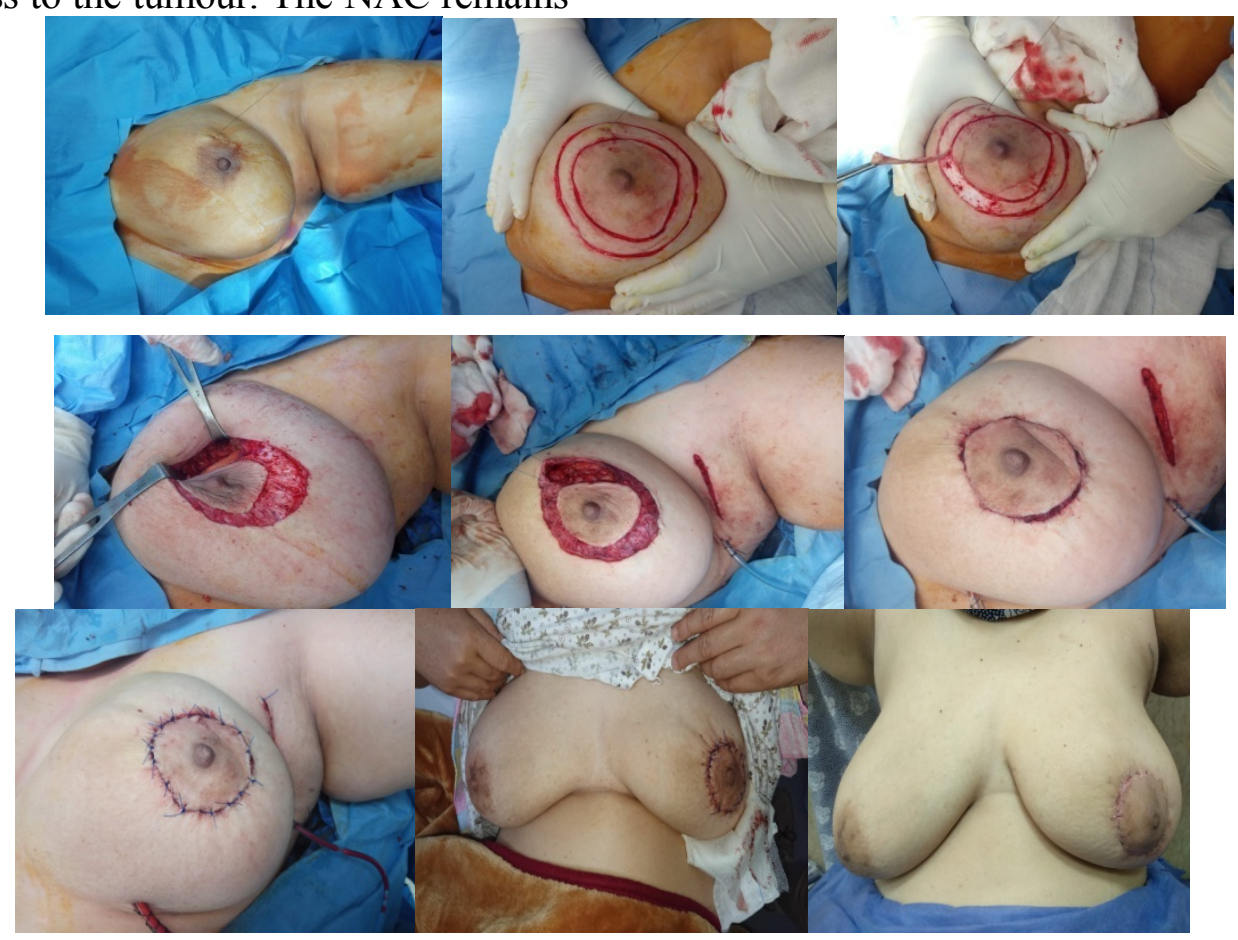

Figure (1): A: Doughnut mastopexy technique (wire localization). B: Preoperative drawings. C: Deepithelialization between outer and inner incision line. D: Excision of the tumor. E: Specimen orientation for frozen section assessment. F: Pectoralis fascia is removed with the specimen and pectoralis major muscle is shown. G: Clipping the tumor bed. H\&I: Closure of the glandular defect and purse string suturing. J: Repositioning and suturing the NAC. K: Early postoperative result. L: Late postoperative result. 
Inferior pedicle mammaplasty technique: Drawings are done preoperatively with the patient in an upright standing position. A central midline is drawn from the sternal notch to the umbilicus. The tumor and the area of breast tissue planned to be resected with the tumor are marked on the skin. A vertical line is drawn from the midclavicular point to the nipple and this line is extended through the nipple to the inframammary fold and on the thoracic wall. The new position of the nipple is marked at the level of the original inframammary fold with this point projected anteriorly on the midclavicular line. An inverted $\mathrm{V}$ is drawn with its peak at the future nipple position. The two lines of the $\mathrm{V}$ are drawn connecting these points to the peak of the V. Horizontal lines are drawn from the end of both lines of the inverted $\mathrm{V}$ and connected to the inframammary fold medially and laterally. The inferior pedicle is outlined on the skin with a base width of 6 to $12 \mathrm{~cm}$. The new areola is marked. The skin is incised along the drawn markings and the inferior pedicle is deepithelialized. Skin flaps of 1 to $2 \mathrm{~cm}$ in thickness are dissected superiorly, medially and laterally down to the pectoralis fascia. The tumor and surrounding tissue is dissected from the inferior pedicle. The specimen is oriented and frozen section examinations are done for margin evaluation. The tumor bed is marked with clips. The inferior pedicle is prepared with a basis of 6 to $12 \mathrm{~cm}$ in width and a thickness of 2 to $6 \mathrm{~cm}$. It is transferred superiorly into the defect then the flaps closed in layers. Contralateral symmetrization is performed in the patients who accepted that preoperatively. Axillary dissection is performed as discussed before.

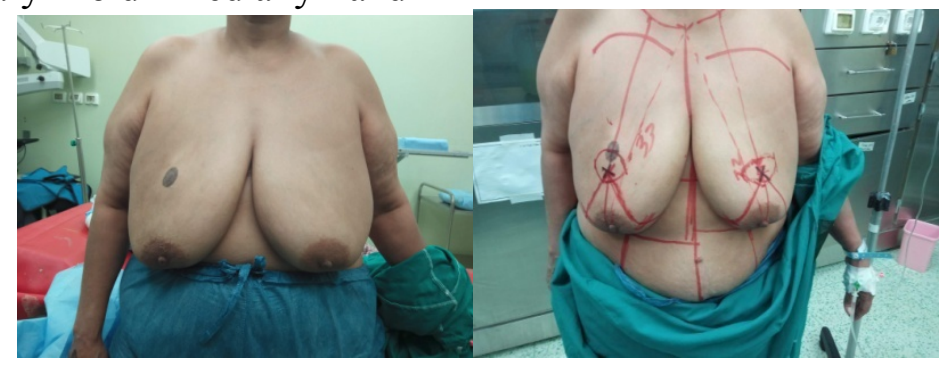

Figure (2): Marking skin for inferior pedicel flap design.

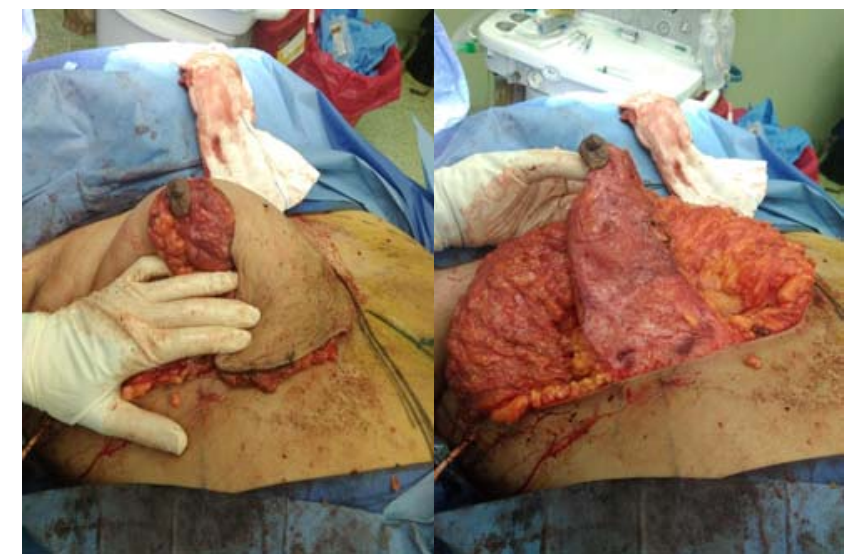

Figure (3): De-epithilization of inferior Pedicaled flap. 


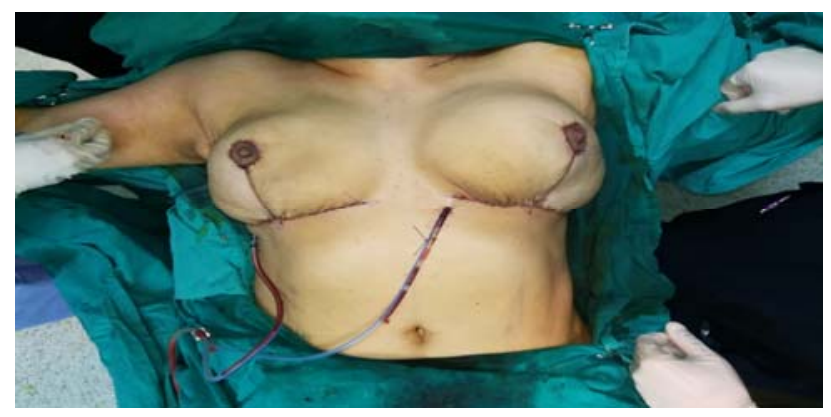

Figure (4): Postoperative contralateral symmetrization.

Patients were assessed Intra-Operatively for:

- Operative time.

- Blood loss.

Post-Operatively patients were assessed for:

\begin{tabular}{|l|l|}
\hline 1st day post & Drainage volume, Hematoma and flap congestion or ischemia \\
\hline Within 1st week & $\begin{array}{l}\text { Drainage volume and days, seroma, wound infection, skin/nipple } \\
\text { sloughing and flap necrosis }\end{array}$ \\
\hline After one month & Scar fibrosis/ dimpling and flap necrosis \\
\hline $\begin{array}{l}\text { Every } 3 \text { months } \\
\text { Up to 1 year }\end{array}$ & $\begin{array}{l}\text { Sonomammography } \\
\text { Aesthetic outcome by patient and surgeon satisfaction }\end{array}$ \\
\hline
\end{tabular}

The Aesthetic outcome score was based on multiple items that made up a check list to be evaluated by our team and the MDT of the breast for every single case. This check list included the overall shape of the breast, the symmetry of both breasts, the site and direction of the nipple, the volume of the breast and the skin incision shape.

\section{Statistical Methodology:}

Analysis of data was done by IBM computer using SPSS (statistical program for social science) as follows: Description of quantitative variables as mean, SD and range. Description of qualitative variables as No. and \%. Unpaired t-test was used to compare two groups as regard quantitative variable. Paired-t-test was used to compare quantitative variable in the same group. $\mathrm{P}$ value $>0.05$ insignificant. $\mathrm{P}<0.05$ significant. $\mathrm{P}<0.01$ highly significant.

\section{RESULTS}

Table (1): Age difference between the two groups.

\begin{tabular}{|c|c|c|c|}
\hline \multirow{2}{*}{ Age } & \multicolumn{2}{|c|}{ Groups } & t-test \\
\cline { 2 - 3 } & Doughnut Mastopexy & Inferior Pedicle Mammaplasty & P-value \\
\hline Range & $30-62$ & $30-64$ & 0.155 \\
\hline Mean \pm SD & $47.40 \pm 8.42$ & $43.07 \pm 7.81$ & \\
\hline
\end{tabular}

Table (2): Family history in the two groups.

\begin{tabular}{|c|c|c|c|}
\hline Family history & $\begin{array}{c}\text { Doughnut } \\
\text { Mastopexy }\end{array}$ & $\begin{array}{c}\text { Inferior Pedicle } \\
\text { Mammaplasty }\end{array}$ & P-value \\
\hline Negative & $8(80 \%)$ & $9(90 \%)$ & 0.543 \\
\hline Positive & $2(20 \%)$ & $1(10 \%)$ & \\
\hline
\end{tabular}


Osama Ali El Atrash, et al.,

Table (3): Comorbidities in the two groups

\begin{tabular}{|c|c|c|c|}
\hline Comorbidities & Doughnut Mastopexy & $\begin{array}{c}\text { Inferior Pedicle } \\
\text { Mammaplasty }\end{array}$ & P-value \\
\hline Negative & $7(70 \%)$ & $6(60 \%)$ & 0.666 \\
\hline Positive & $3(30 \%)$ & $4(40 \%)$ & \\
\hline
\end{tabular}

Table (4): Tumor size in the two groups.

\begin{tabular}{|l|c|c|c|}
\hline \multirow{2}{*}{$\begin{array}{c}\text { Tumor size } \\
(\mathrm{mm})\end{array}$} & \multicolumn{2}{|c|}{ Groups } & t-test \\
\cline { 2 - 3 } & Doughnut Mastopexy & Inferior Pedicle Mammaplasty & P-value \\
\hline Range & $8-29$ & $10-32$ & 0.733 \\
\hline Mean \pm SD & $18.5 \pm 5.23$ & $20.1 \pm 6.09$ & \\
\hline
\end{tabular}

Table (5): The distance of the tumor from the nipple in the two groups.

\begin{tabular}{|c|c|c|c|}
\hline \multirow{2}{*}{$\begin{array}{c}\text { Distance of the tumor from } \\
\text { the nipple }(\mathrm{cm})\end{array}$} & \multicolumn{2}{|c|}{ Groups } & t-test \\
\cline { 2 - 3 } & Doughnut Mastopexy & Inferior Pedicle Mammaplasty & P-value \\
\hline Range & $1.5-10$ & $1.5-11.5$ & 0.539 \\
\hline Mean \pm SD & $6.02 \pm 2.42$ & $6.35 \pm 3.29$ & \\
\hline
\end{tabular}

Table (6): Difference in the operative time in the two groups.

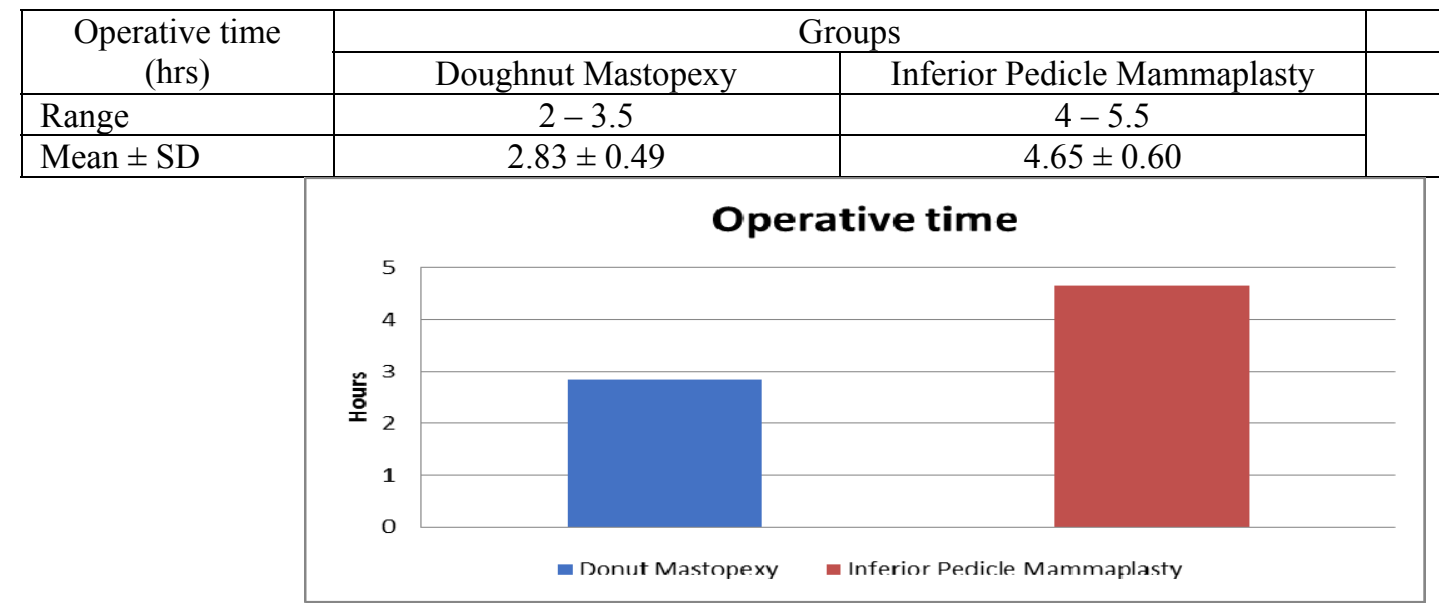

Figure (5): Operative time.

Table (7): Intraoperative blood loss in the two groups.

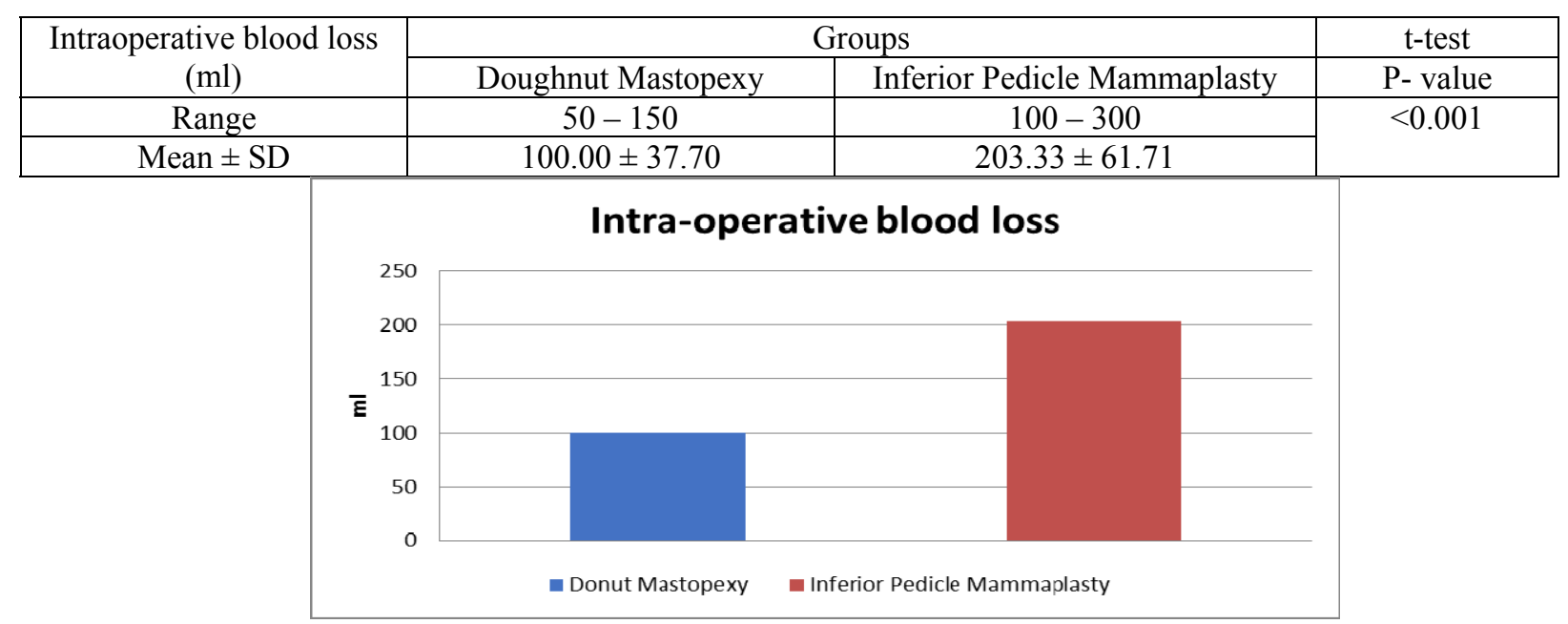

Figure (6): Intra-operative blood loss. 
Oncoplastic techniques for early upper inner quadrant breast cancer; a comparative study....

Table (8): Contralateral surgery in the two groups

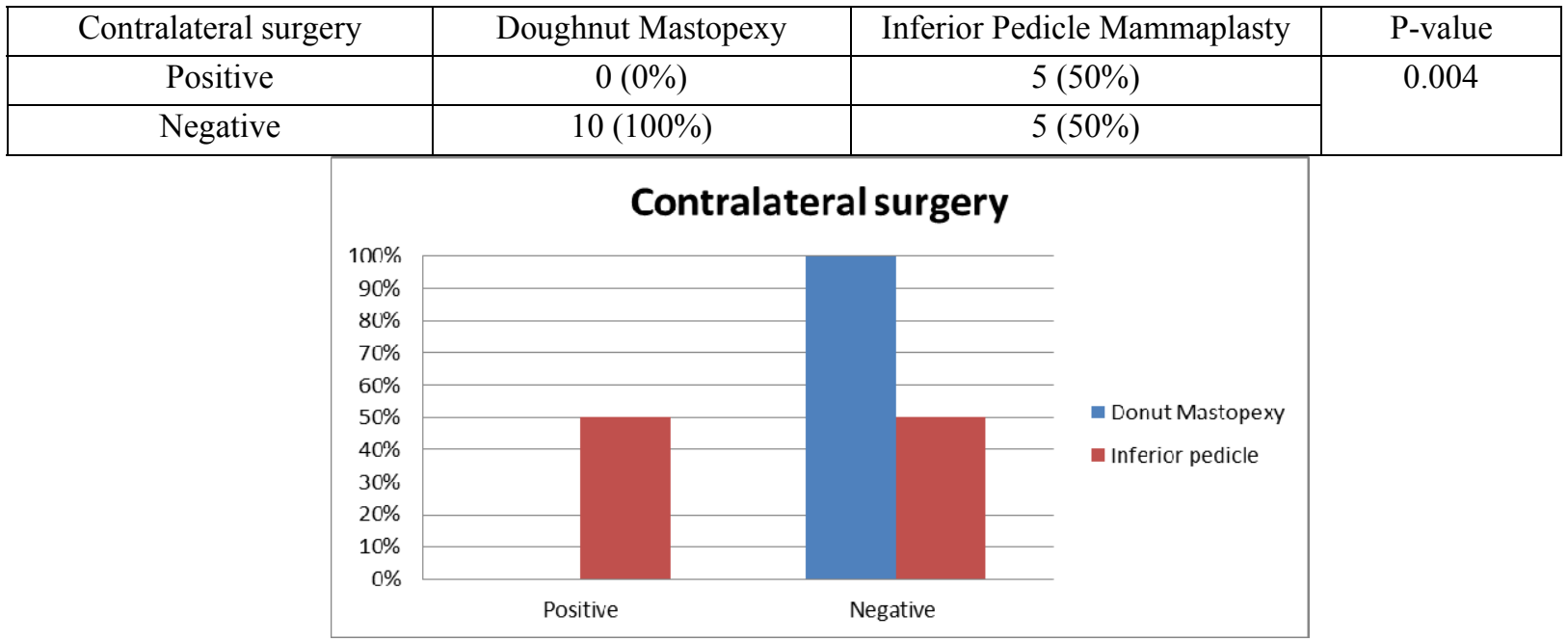

Figure (7): Contralateral surgery.

Table (9): Total drainage volume in the two groups.

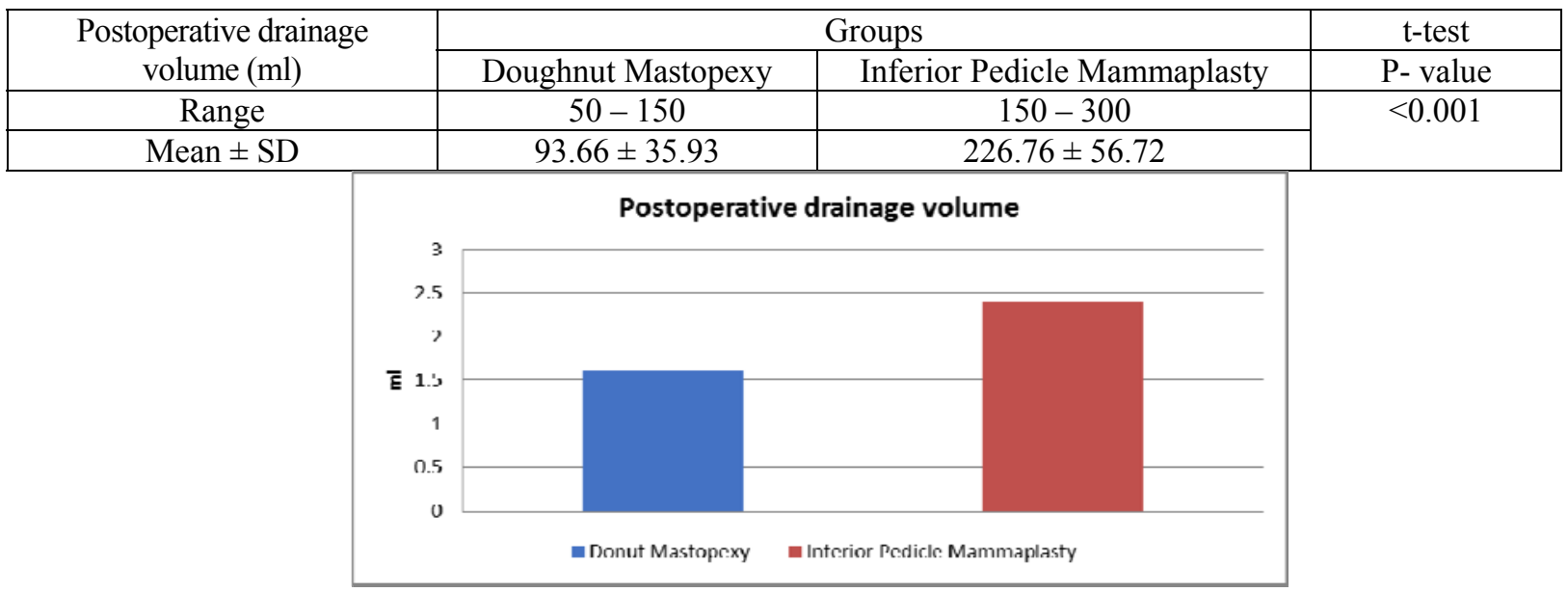

Figure (8): Postoperative drainage volume.

Table (10): Total drainage days in the two groups.

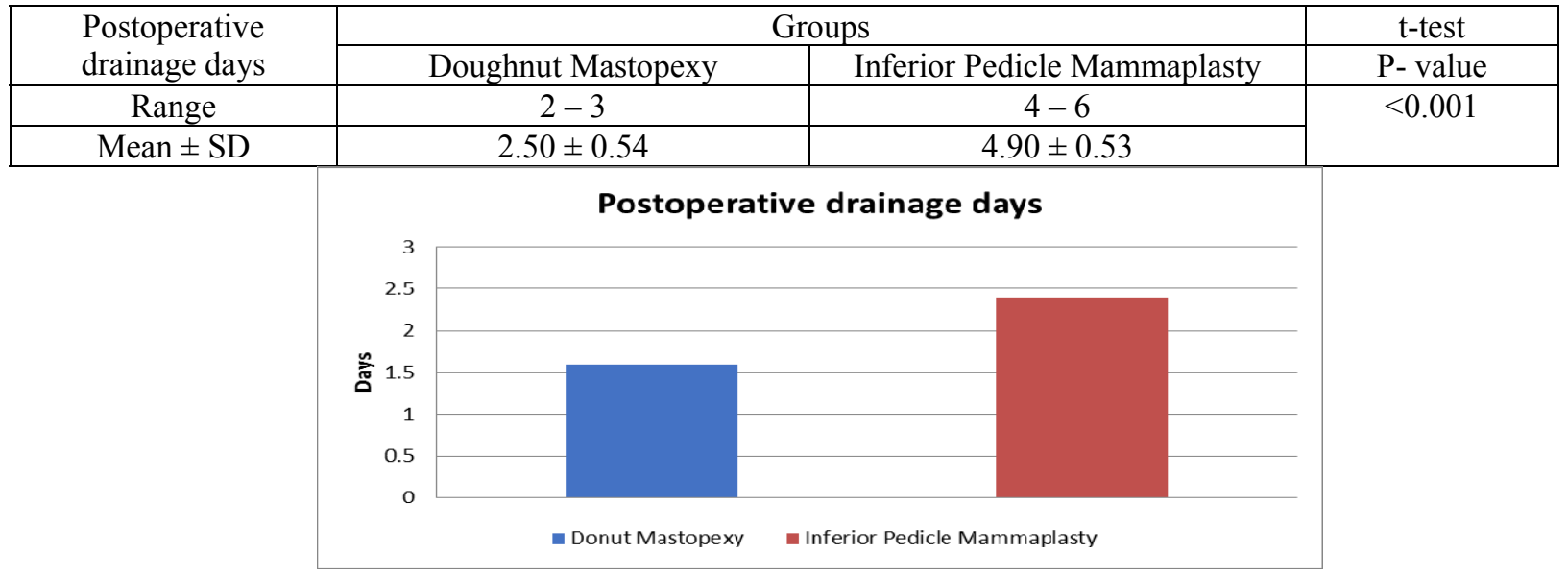

Figure (9): Postoperative drainage days. 


\section{Osama Ali El Atrash, et al.,}

Table (11): Hospital stay in the two groups.

\begin{tabular}{|c|c|c|c|}
\hline $\begin{array}{c}\text { Postoperative hospital stay } \\
\text { (days) }\end{array}$ & \multicolumn{2}{|c|}{ Groups } & t-test \\
\cline { 2 - 3 } & Doughnut Mastopexy & Inferior Pedicle Mammaplasty & P-value \\
\hline Range & $1-2$ & $1-3$ & $<0.001$ \\
\hline Mean \pm SD & $1.60 \pm 0.48$ & $2.40 \pm 0.70$ & \\
\hline
\end{tabular}

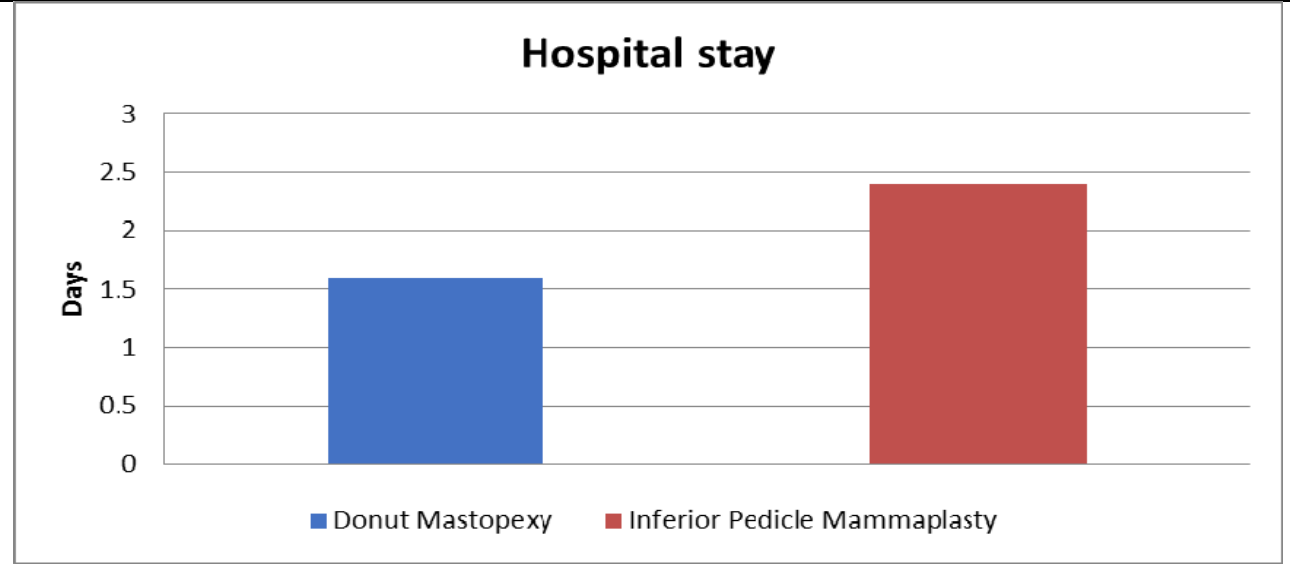

Figure (10): Hospital stay.

Table (12): Seroma formation rate in the two groups.

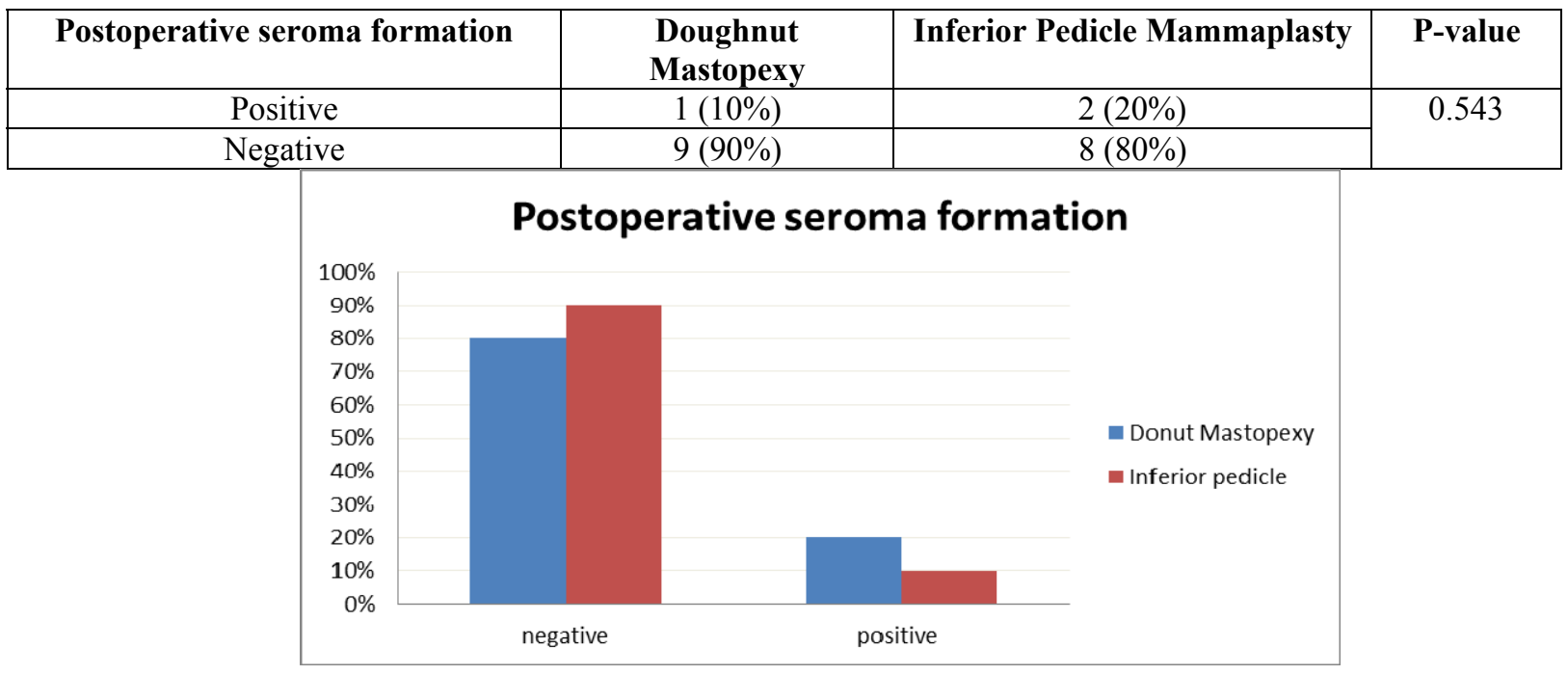

Figure (11): Postoperative seroma formation.

Table (13): Hematoma formation in the two groups.

\begin{tabular}{|c|c|c|c|}
\hline Hematoma formation & Doughnut Mastopexy & Inferior Pedicle Mammaplasty & P-value \\
\hline Positive & $1(10 \%)$ & $0(0 \%)$ & 0.543 \\
\hline Negative & $9(90 \%)$ & $10(100 \%)$ & \\
\hline
\end{tabular}


Oncoplastic techniques for early upper inner quadrant breast cancer; a comparative study....

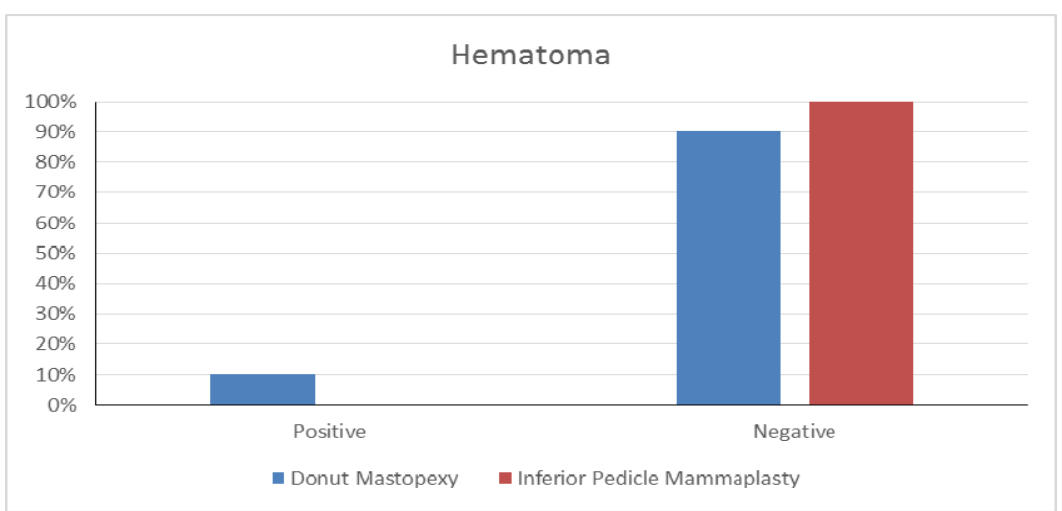

Figure (12): Hematoma.

Table (14): Wound infection in the two groups.

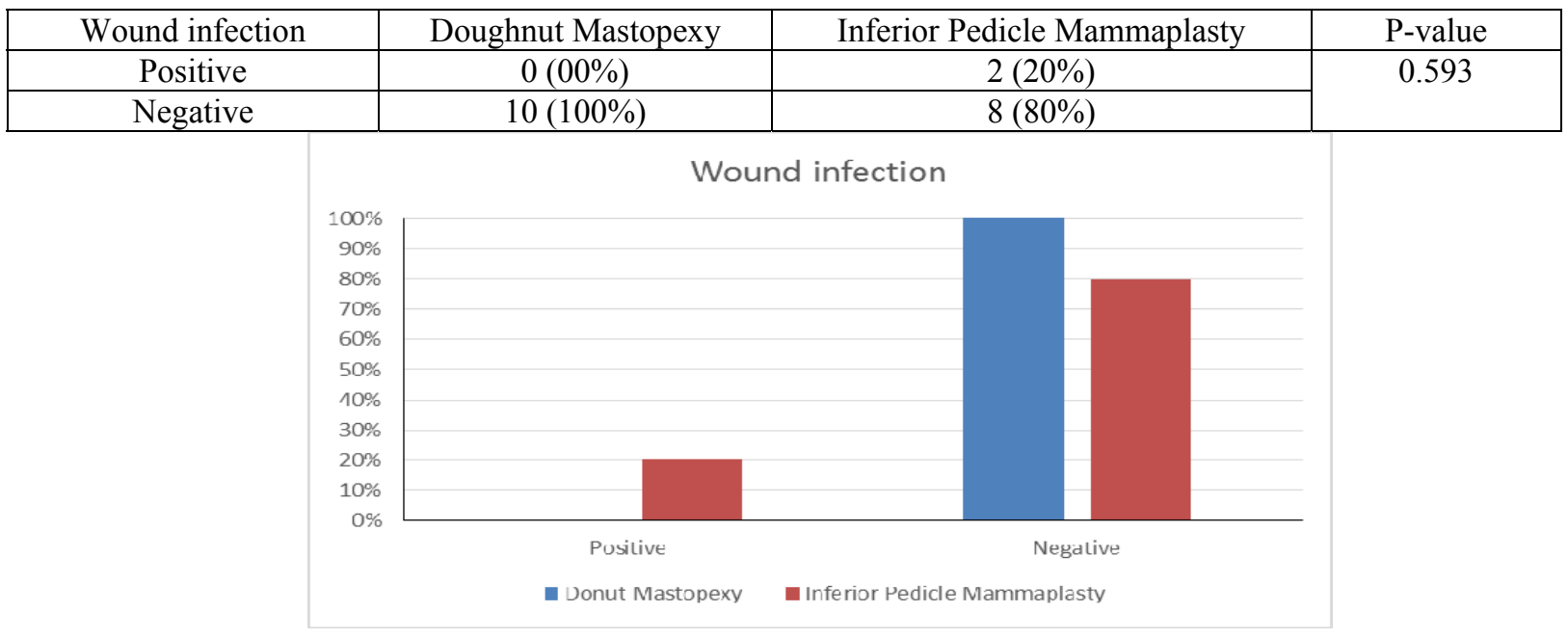

Figure (13): Wound infection.

Table (15): Partial NAC necrosis in both groups.

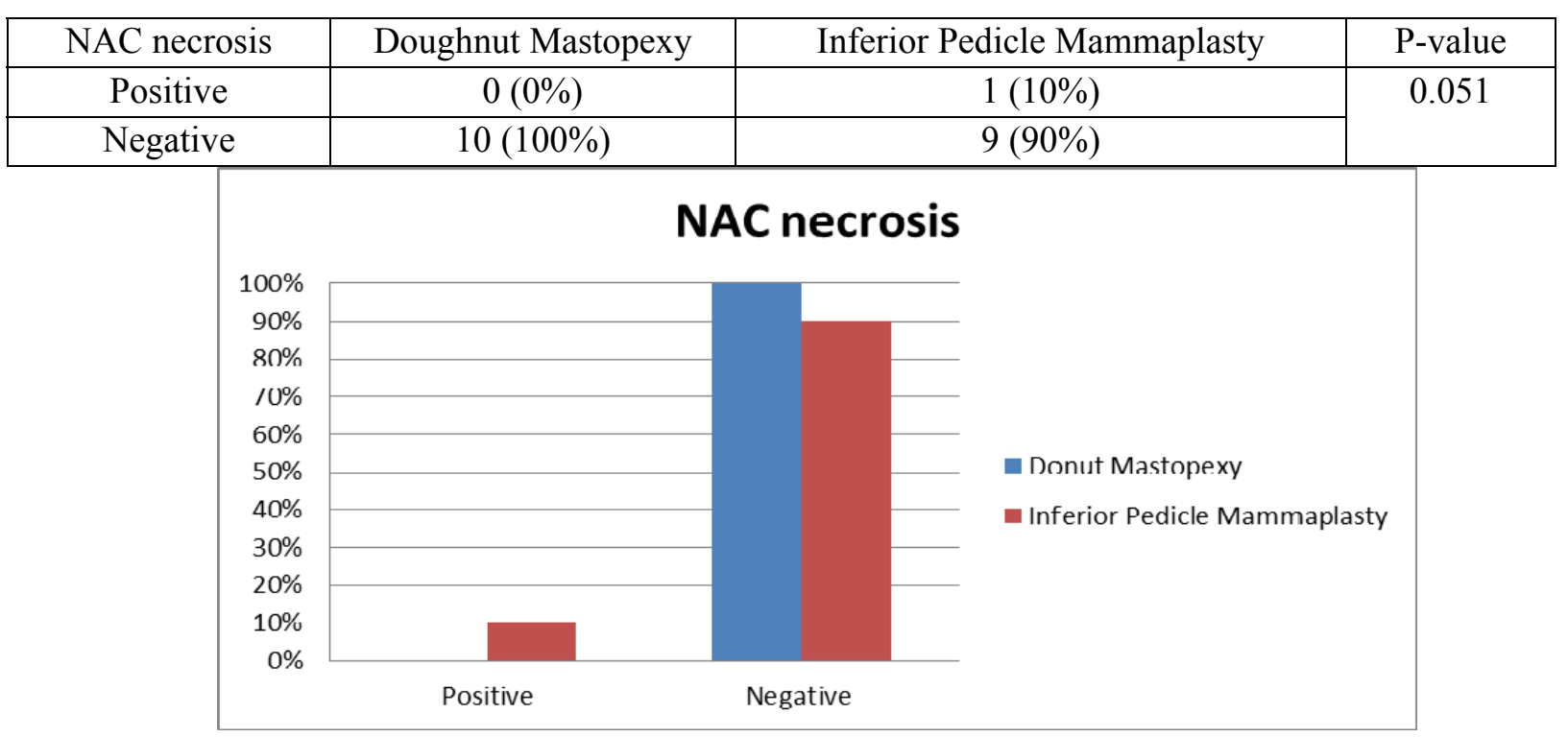

Figure (14): NAC necrosis. 
Osama Ali El Atrash, et al.,

Table (16): Wound dehiscence in both groups.

\begin{tabular}{|c|c|c|c|}
\hline Wound dehiscence & Doughnut Mastopexy & Inferior Pedicle Mammaplasty & P-value \\
\hline Positive & $0(0 \%)$ & $2(20 \%)$ & 0.028 \\
\hline Negative & $10(100 \%)$ & $8(80 \%)$ & \\
\hline
\end{tabular}

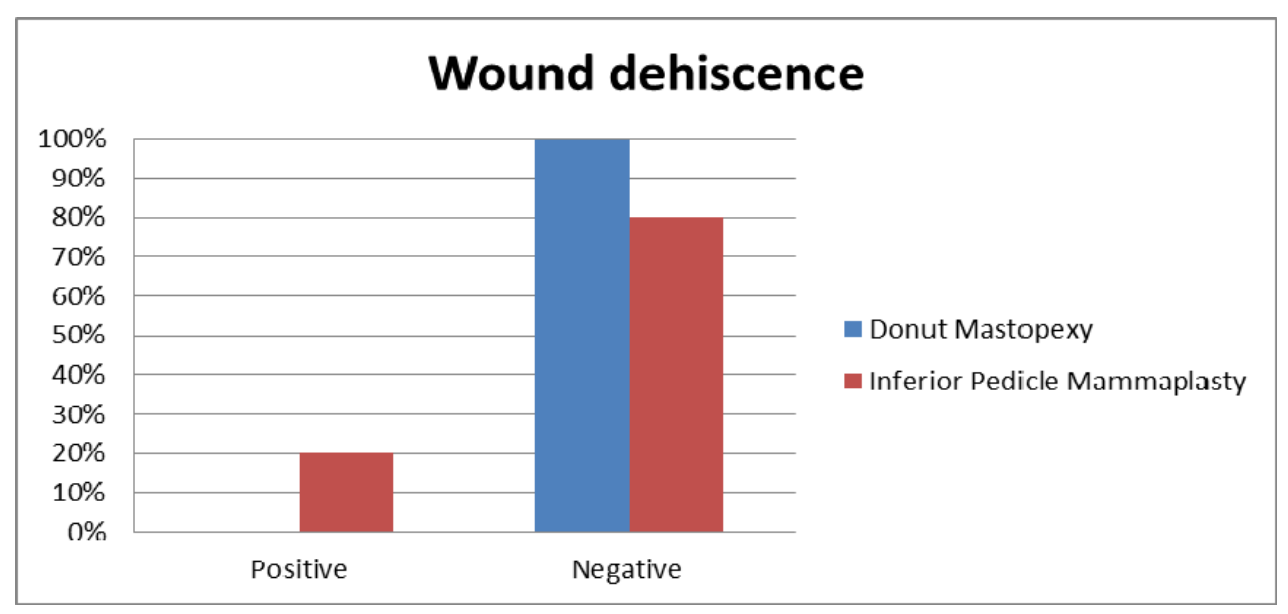

Figure (15): Wound dehiscence.

Table (17): Cosmetic outcome.

\begin{tabular}{|c|c|c|c|}
\hline Cosmetic outcome & Doughnut Mastopexy & $\begin{array}{c}\text { Inferior Pedicle } \\
\text { Mammaplasty }\end{array}$ & P-value \\
\hline Excellent & $8(80 \%)$ & $2(20 \%)$ & \multirow{2}{*}{0.019} \\
\hline Good & $2(20 \%)$ & $3(30 \%)$ & \\
\hline Fair & $0(0 \%)$ & $3(30 \%)$ & \\
\hline Poor & $0(0 \%)$ & $2(20 \%)$ & \\
\hline
\end{tabular}

\section{Cosmetic outcome}

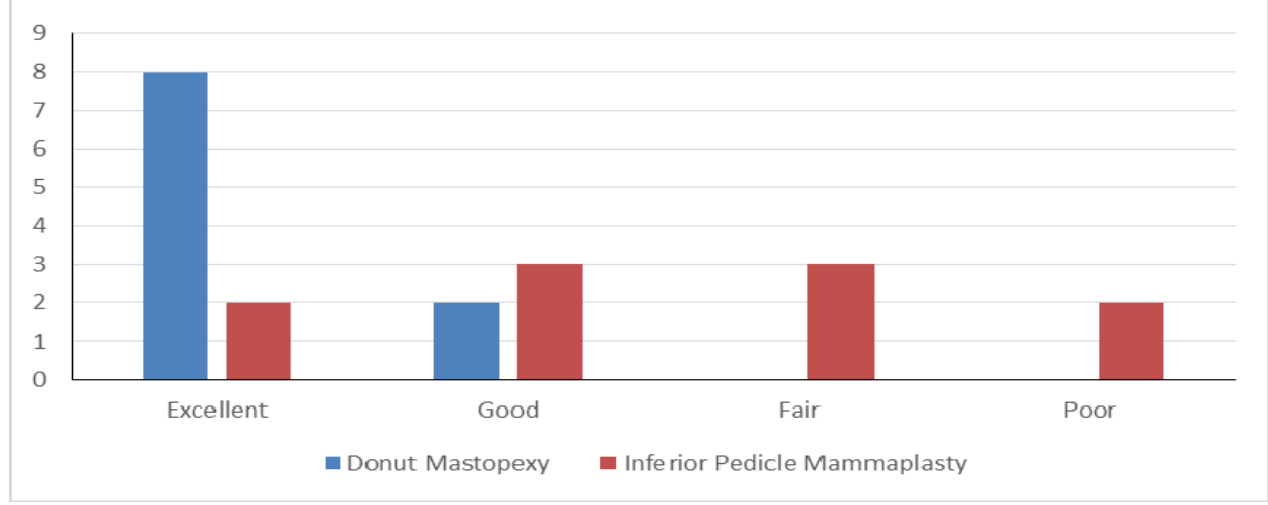

Figure (16): Cosmetic outcome.

Table (18): Local recurrence.

\begin{tabular}{|c|c|c|}
\hline Local recurrence & Doughnut Mastopexy & Inferior Pedicle Mammaplasty \\
\hline Positive & $0(0 \%)$ & $0(0 \%)$ \\
\hline Negative & $10(100 \%)$ & $10(100 \%)$ \\
\hline
\end{tabular}




\section{DISCUSSION:}

Breast cancer is the most frequent carcinoma in females, diagnosed in 1.4 million women in the US every year and has been the most common cause for cancer mortality in women. Even with new progress in screening, diagnostics and surgery, there are still a lot left to be desired ${ }^{(15)}$.

Breast cancer has been threatening human health for a long time and multiple researches have been carried out to investigate the underlying mechanism of breast cancer and its treatment ${ }^{(\mathbf{1 6})}$.

Landmark trials have established that breast conservation therapy and mastectomy offer equivalent survival and can be viewed as equivalent treatments in early stage breast cancer $^{(17)}$.

The main rationale for neoadjuvant therapy for breast cancer is to provide effective systemic treatment while surgically down-staging the cancer. This down-staging was initially to convert inoperable patients to operable and later to increase rates of breast conservation in patients initially deemed mastectomy only candidates ${ }^{(18)}$.

Approximately $10 \%$ to $30 \%$ of patients submitted to breast conservation surgery are not satisfied with the aesthetic outcome. The main reasons are related to the tumor resection which can produce retraction and volume changes in the breast. In addition, radiation can also have a negative effect on the native breast. The main clinical aspects are related to skin pigmentation changes, telangiectasia, and skin fibrosis ${ }^{(19)}$.

Surgical techniques involving breast cancer have recently evolved in three important areas: patient recovery, oncological safety and optimal cosmetic outcome ${ }^{(20)}$.

Four main factors influence the extent of breast deformity after breast conservation: tumor location, tumor to breast size ratio, use of radiotherapy and surgical resection $\operatorname{approach}^{(21)}$.
The size and location of the defect are two of the major factors affecting the postoperative cosmetic outcome after partial mastectomy. The ratio of breast volume excised is an important factor to determine the cosmetic result and patient satisfaction after oncoplastic breast surgery. Studies have suggested that excision of $10-12 \%$ of the breast volume predicted poor cosmoses. The location of the defect after partial mastectomy is also a major influence on the cosmetic outcome. For instance, surgery for upper inner quadrant cancers is associated with a poor cosmetic result even in cases with a small defect ${ }^{(22)}$.

In our study, we divided the study sample into two groups and we compared between Doughnut mastopexy (Group I) and Inferior pedicle mammaplasty (Group II) in treatment of early breast cancer located in the upper inner quadrant.

In our study, there was no significant statistical difference between the two groups as regards the patients' age, with the mean age of 47.4 years (30-62 years) and 43.07 years (30-64 years) in group (I) (Doughnut mastopexy) and group (II) (Inferior pedicle mammaplasty) respectively. This was relatively lower than the mean age of the patients who participated in the study carried out by Rose et al. ${ }^{(23)}$ which was 53 years. Moreover, the mean age was higher in some studies such as that carried out by Tenofsky et al. ${ }^{(24)}$ which was 60.9 years. The mean age of the patients was 53.3 years in the mastopexy group in the study carried out by Eichlier et al. ${ }^{(25)}$. The mean age of the patients was 50 years in the reduction mammaplasty group in the study carried out by Emirolgu et al. ${ }^{(26)}$.

Relatively younger age of the included patients increased the cosmetic and aesthetic demands. This made patient satisfaction a more challenging goal.

In our study there was positive first degree family history in $20 \%$ of the patients 
in group (I) (Doughnut mastopexy) and positive second degree family history in $10 \%$ of the patients in group (II) (Inferior pedicle mammaplasty). Unfortunately BRCA gene test, which is related to significantly positive family history, was not available in our hospitals during this study.

In our study, there was no significant statistical difference between the two groups as regards the tumor distance from the nipple. In group (I) (Doughnut mastopexy) it ranged from $1.5-10 \mathrm{~cm}$ with mean distance $6.02 \mathrm{~cm}$ and in group (II) (Inferior pedicle mammaplasty) it ranged from $1.5-11.5 \mathrm{~cm}$ with mean distance $6.35 \mathrm{~cm}$. This was higher than those of patients included in the study carried out by Chen ${ }^{(27)}(2-6 \mathrm{~cm}$ apart from the center of the nipple). Therefore, both techniques are available options for patients with distant lesions from the nipple areola complex but these lesions add some technical difficulty of doughnut mastopexy.

There was significant statistical difference in both group as regards the operative time, intraoperative blood loss, hospital stay, postoperative drainage volume and days, postoperative complications and cosmetic outcome as regards patient and surgeon satisfaction. These are comparable to some studies as follow:

As regards the operative time and the intraoperative blood loss, in our study, the operative time was longer and blood loss was more in group (II) (Inferior pedicle mammaplasty) than group (I) (Doughnut mastopexy) with mean: 4.65 hours, and 100$300 \mathrm{ml}$ (average $203.33 \mathrm{ml}$ ) in group (II) versus mean: 2.83 hours, and $50-150 \mathrm{ml}$ (average $100 \mathrm{ml}$ ) in group (I).

Ogawa ${ }^{(28)}$ in his study of 18 patients reported mean operative time 3 hours (range 188-191minutes) in the doughnut mastopexy group.

Emirolgu et al. ${ }^{(26)}$ in their study of 82 patients reported that the average operative time in the reduction mammaplasty group was 2.5 hours (range 80-190 minutes)

In our study, we found that the mean hospital stay was 1.6 days (range 1-2 days) in group (I) (Doughnut mastopexy) versus 2.4 days (1-3 days) in group (II) (Inferior pedicle mammaplasty).

Regarding the postoperative complications, Emirolgu et al. ${ }^{(26)}$ in a total of 82 patients that underwent oncoplastic reduction mammasplasty the overall rate of complications was $12.2 \% \quad(10 / 82)$. Four patients developed wound dehiscence, one patient developed areola necrosis, three patients developed seroma and two patients developed wound site infection.

Ogawa ${ }^{(28)}$ in a total of 18 patients that underwent round block technique, four patients had blood flow insufficiency in part of the NAC.

In our study, patients have experienced some complications. In group (I) (Doughnut mastopexy), one patient developed seroma and another one had hematoma. In group (II) (Inferior pedicle mammaplasty), two patients developed seroma, one had wound infection, two had wound dehiscence and one had partial NAC necrosis.

In our study we reported the cosmetic outcome according to subjective patient satisfaction and subjective surgeon satisfaction to the final breast shape and it was $80 \%$ excellent and $20 \%$ good in group (I) (Doughnut mastopexy). While in group (II) (Inferior pedicle mammaplasty) it was excellent in $20 \%$, good in $30 \%$, fair in $30 \%$ and poor in $20 \%$. The $50 \%$ in group (II) (Inferior pedicle mammaplasty) that underwent contralateral breast surgery for symmetrization are those who were given excellent and good cosmetic result.

Zaha et al. ${ }^{(29)}$, in a total of 40 patients that underwent modified round block technique, the cosmetic outcome was excellent in $65 \%$, good in $25 \%$, fair in $7.5 \%$ and poor in $2.5 \%$. 
Denewer et al. ${ }^{(30)}$, in a total of 50 patients that underwent reduction mammoplasty group, the cosmetic outcome was $64 \%$ excellent, $30 \%$ showed good results and $6 \%$ rated the outcome as fair.

In our study, there was no local recurrence for 12 months. Niinikoski et al. (31), local recurrence rate during a median of 75 months follow-up was $2.3 \%$. This is comparable to other studies. Romics et al. ${ }^{(32)}$, reported a local recurrence rate of $2.7 \%$ during a median of 30 months follow-up and Clough et al. ${ }^{(33)}$, a local recurrence rate of $2.2 \%$ during a median of 55 months followup.

\section{Conclusion:}

Patients with early breast cancer located in the upper inner quadrant are candidate for either Inferior pedicle mammaplasty or Doughnut mastopexy. Doughnut mastopexy is better for them as there is less morbidity, better cosmesis, no need for contralateral symmetrization and fewer complications, so no delay in radiotherapy and Inferior pedicle mammaplasty needs more surgeon experience.

\section{REFERENCES:}

1. Urban C (2013): Oncoplastic and reconstructive breast surgery. M. Rietjens (Ed.): Milan: Springer.

2. Bohon C (2017): Cancer recognition and screening for common breast disorders and malignancy. Obstetrics and Gynecology Clinics, 44(2): 257-270.

3. Ahmed AR (2016): HER 2 expression is a strong independent predictor of nodal metastasis in breast cancer. Journal of the Egyptian National Cancer Institute, 28(4): 219-227.

4. Holmes DR, Schooler W and Smith R (2011): Oncoplastic approaches to breast conservation. International journal of breast cancer, 2011.
5. Yan SH (2013): An early history of human breast cancer: West meets East. Chinese journal of cancer, 32(9): 475.

6. Silverstein MJ (2016): Radical mastectomy to radical conservation (extreme oncoplasty): a revolutionary change. Journal of the American College of Surgeons, 222(1): 1-9.

7. Lin J, Chen DR, Wang YF, et al. (2016): Oncoplastic surgery for upper/upper inner quadrant breast cancer. PloS one, 11(12): e0168434.

8. Fajdic J, Djurovic D, Gotovac N, et al. (2013): Criteria and procedures for breast conserving surgery. Acta Informatica Medica, 21(1): 16.

9. Urban C, Lima R, Schunemann E, et al. (2011): Oncoplastic principles in breast conserving surgery. The breast, 20, S92S95.

10. Zucca-Matthes G, Manconi A, da Costa Viera RA, et al. (2013): The evolution of mastectomies in the oncoplastic breast surgery era. Gland surgery, 2(2): 102.

11. Clough KB, Kaufman GJ, Nos C, et al. (2010): Improving breast cancer surgery: a classification and quadrant per quadrant atlas for oncoplastic surgery. Annals of surgical oncology, 17(5): 1375-1391.

12. Zaha H (2015): Oncoplastic volume replacement technique for the upper inner quadrant using the omental flap. Gland surgery, 4(3): 263.

13. Piper M, Peled AW and Sbitany H (2015): Oncoplastic breast surgery: current strategies. Gland surgery, 4(2): 154.

14. Matsuzaki K (2012): Breast Surgery with Application of Doughnut Mastopexy Lumpectomy Technique. Modern Plastic Surgery, 2(04): 91.

15. Wang $\mathrm{P}, \mathrm{Du} \mathrm{Y}$ and Wang J (2019): Indentification of breast cancer subtypes sensitive to HCQ-induced autophagy inhibition. Pathology-Research and Practice, 215(10): 152609.

16. Bonilla JM, Tabanera MT and Mendoza LR (2017): Breast cancer in the 21st century: From early detection to new therapies. 
Radiología (English Edition): 59(5): 368379.

17. Gu J, Groot G, Boden C, et al. (2018): Review of factors influencing women's choice of mastectomy versus breast conserving therapy in early stage breast cancer: a systematic review. Clinical breast cancer, 18(4): 539-554.

18. Criscitiello C, Curigliano G, Burstein HJ, et al. (2016): Breast conservation following neoadjuvant therapy for breast cancer in the modern era: are we losing the opportunity? European Journal of Surgical Oncology (EJSO): 42(12): 1780-1786.

19. Agha RA, Fowler AJ, Herlin $\mathrm{C}$, et al. (2015): Use of autologous fat grafting for breast reconstruction: a systematic review with meta-analysis of oncological outcomes. Journal of Plastic, Reconstructive \& Aesthetic Surgery, 68(2): 143-161.

20. Laronga $C$, Lewis JD and Smith PD (2012): The changing face of mastectomy: an oncologic and cosmetic perspective. Cancer Control, 19(4): 286-294.

21. Habibi M, Broderick KP, Sebai ME, et al. (2018): Oncoplastic Breast Reconstruction: Should All Patients be Considered? Surgical Oncology Clinics, 27(1): 167-180.

22. Lee S, Lee J, Jung $Y$, et al. (2017): Oncoplastic surgery for inner quadrant breast cancer: fishhook incision rotation flap. ANZ journal of surgery, 87(10): E129-E133.

23. Rose $M$, Manjer $J$, Ringberg $A$, et al. (2014): Surgical strategy, methods of reconstruction, surgical margins and postoperative complications in oncoplastic breast surgery. European journal of plastic surgery, 37(4): 205-214.

24. Tenofsky PL, Dowell P, Topalovski T, et al. (2014): Surgical, oncologic, and cosmetic differences between oncoplastic and nononcoplastic breast conserving surgery in breast cancer patients. The American Journal of Surgery, 207(3): 398-402.

25. Eichler C, Kolsch M, Sauerwald A, et al. (2013): Lumpectomy versus mastopexy-a post-surgery patient survey. Anticancer research, 33(2): 731-736.

26. Emiroglu M, Karaali C, Salimoglu S, et al. (2016): Oncoplastic reduction mammoplasty for breast cancer in women with macromastia: long term aesthetic, functional and satisfaction outcomes. Contemporary oncology, 20(3): 256.

27. Chen DR (2014): An optimized technique for all quadrant oncoplasty in women with small-to medium-sized breasts. Eur Rev Med Pharmacol Sci, 18(12): 1748-54.

28. Ogawa T (2014): Usefulness of breastconserving surgery using the round block technique or modified round block technique in Japanese females. Asian journal of surgery, 37(1): 8-14.

29. Zaha $H$, Onomura $M$ and Unesoko $M$ (2013): A new scarless oncoplastic breastconserving surgery: modified round block technique. The Breast, 22(6): 1184-1188.

30. Denewer A, Shahatto F, Elnahas W, et al. (2012): Therapeutic reduction mammoplasty in large-breasted women with cancer using superior and superomedial pedicles. Breast Cancer: Targets and Therapy, 4, 167.

31. Niinikoski L, Leidenius $M H$, Vaara $P$, et al. (2019): Resection margins and local recurrences in breast cancer: Comparison between conventional and oncoplastic breast conserving surgery. European Journal of Surgical Oncology, 45(6): 976982.

32. Romics L, Macaskill EJ, Fernandez T, et al. (2018): A population-based audit of surgical practice and outcomes of oncoplastic breast conservations in Scotland-An analysis of 589 patients. European Journal of Surgical Oncology, 44(7): 939-944.

33. Clough KB, van la Parra RF, Thygesen $\mathrm{HH}$, et al. (2018): Long-term results after oncoplastic surgery for breast cancer: a 10 year follow-up. Annals of surgery, 268(1): $165-171$. 
تقييم جراجات أورام الثدي التجميلية لسرطان الثدي المبكر في الربع العلوي الداخلي؛ دراسة مقارنة

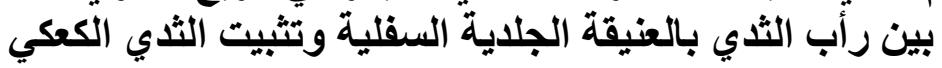

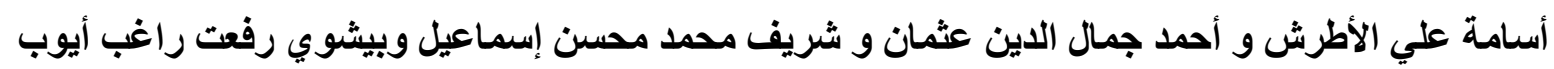

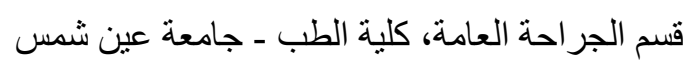

المقدمه: اصبحت جراحات استئصال الثدي التحفظي هي العلاج الأمثل لسرطان الثدي المبكر وهدفها هو توفير

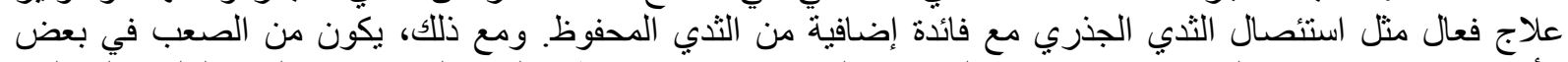

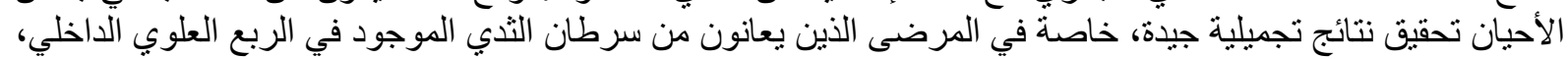

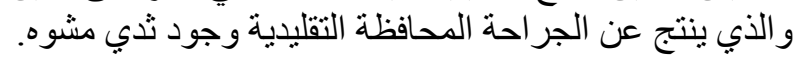

الهاف: مقارنة بين رأب الثدي بالعنيقة الجلدية السفلية وتثيتيت الثذي الكعكي في حالات أورام الثاي المبكر في الربع

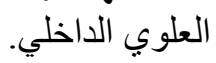

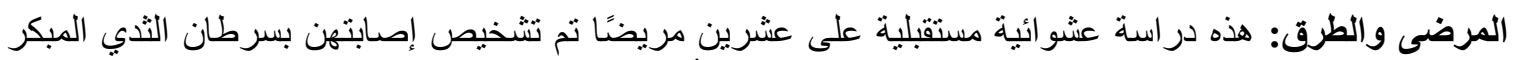

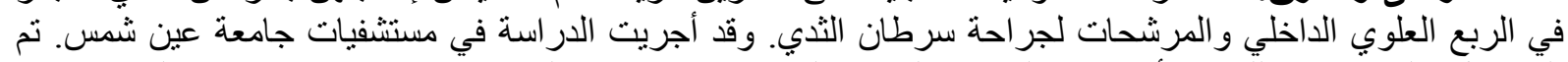

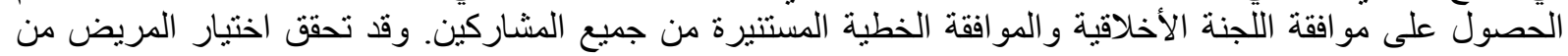
خلال عدد من معايير الاشتمال والاستبعاد.

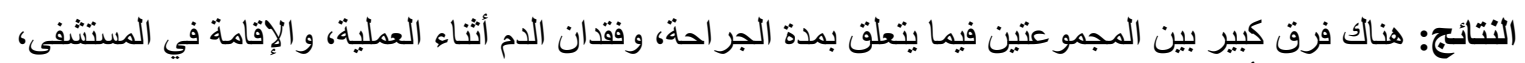

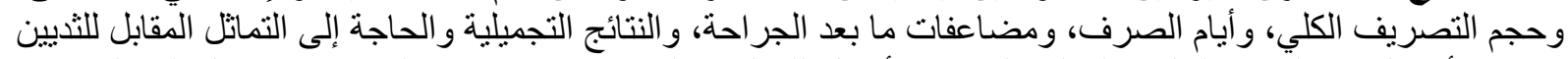

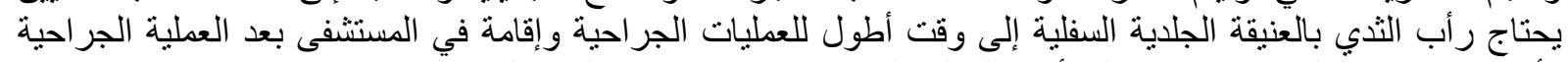
وأيام تصريف مع المزيد من فقدان الدم أثناء العملية الجر احية مقارنة بنتيبيث الثذبي الكعكي.

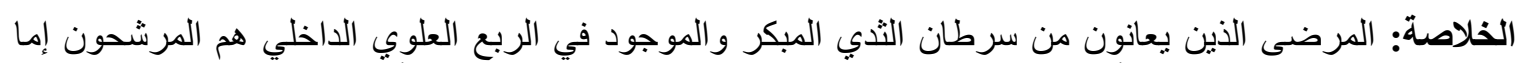

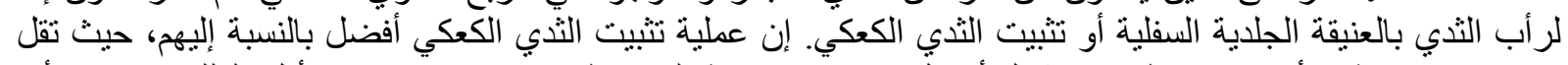

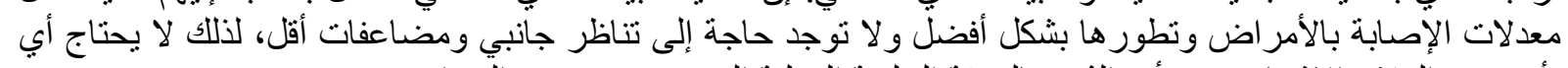

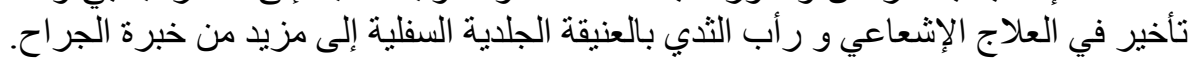

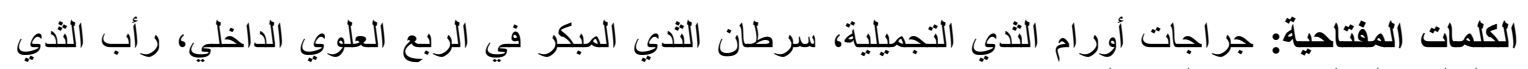
بالعنيقة الجلدية السفلية، تثييت الثدي الكعكي 